\title{
Coping Strategies of the Students of Different Ethnic Groups
}

\author{
Julia Alexandrovna Afanasyeva \\ Senior Lecturer \\ North Ossetian State University named \\ after K.D. Khetagurov \\ afanaseva.y@mail.ru \\ Victoria Vladimirovna Ilchenko \\ Ph.D. of psychology, Associate Professor \\ North Ossetian State University named \\ after K.D. Khetagurov \\ vilchen@mail.ru
}

\author{
Leila Izmailovna Doeva \\ Ph.D. of psychology, Associate Professor \\ North Ossetian Pedagogical Institute \\ ya.leila-doeva@yandex.ru
}

\author{
Svetlana Dzakhotovna Gurieva \\ Ph.D. of psychology, Professor \\ Saint Petersburg State University \\ gurievasv@gmail.com
}

\author{
Valery Leonidovich Sitnikov \\ Ph.D. of psychology, Professor \\ Russian State Pedagogical University named \\ after A. I. Gerzen \\ sitnikof@mail.ru
}

\begin{abstract}
The transformation of the Russian society in the recent decades led to a change in the system of values, needs and behavior of young people. In the context of a serious crisis of moral attitudes, the intensification of the global trend towards the aggravation of ethnocultural contradictions, worsening of the demographic situation in Russia, the problems of studying crosscultural characteristics of coping strategies among young men and women acquires prime priority. Knowledge and consideration of age and ethnopsychological factors affecting students' coping strategies are of great importance for interethnic interaction in society. The article describes and analyzes an empirical study of cross-cultural characteristics of coping strategies among young men and women of Russian and Ossetian ethnic groups. The study sample included 216 people aged 18 to 23 years (average age 21.5) living in the Republic of North Ossetia-Alania. The obtained results contribute to the enrichment of scientific ideas related to the influence of cross-cultural, gender, and age factors on the process of forming coping strategies among students. The data obtained can be used as basic principles in the organization of socio-psychological services in multicultural regions, as well as in the development of training programs in stress psychology, personality psychology, ethnic psychology, age psychology, and developmental psychology.
\end{abstract}

Keywords-ethnos, coping strategies, problem-oriented coping, emotionally-oriented coping, sexual behavior

\section{INTRODUCTION}

The growing dynamics of the modern life rhythm accounts for the existence of many stress factors in professional activities, family, and personal life and challenge the individual with immediate and constructive overcoming of them. The direction of personal development, the state of psychosomatic health, social adaptation and psychological well-being will depend on the efficiency of handling with difficult life situations. The use of various methods and techniques aimed at overcoming stressful situations is called coping strategies (from the English "coping" - psychological overcoming). In Russian psychology, the term "coping strategies" denotes the concept of "coping with stress".

In recent years there is a steady continual increase in research on coping with stress, and coping strategies are no longer considered to be an understudied field of cognitive and behavioral efforts to manage psychological stress. Foreign and Russian psychologists attribute coping strategies to constructive forces that initiate the individual's transformative activity directed at the world and himself. Also, most researchers attribute coping strategies to a system of goaldirected actions aimed at predicting the outcome of any process, creatively generating new conclusions and solutions to difficult, stressful situations.

The study of coping strategies as an essential component of adaptive social behavior is important in connection with the ongoing social instability in the modern society, the existence of conflicting development trends including negative ones (crime, violence, unemployment, divorce, etc.). The particular vulnerability of young people striving for self-affirmation and success in life serves as the basis for developing this issue with the aim of introducing psychological assistance programs for adaptation, overcoming difficulties on their own and with the help of other people, through increasing stress resistance, resilience, and developing constructive ways to cope with stress $[1,7]$. 
Most authors agree that coping strategies are an important internal resource of an individual. Depending on the degree of constructiveness, behavior models can contribute to or hinder the success of stress management in any area of a person's life. Overcoming any stress factors with the help of coping strategies contributes to the actualization of personal potentials and finding better comprehension of the meaning of life. In this regard, the study of cross-cultural and gender characteristics of coping behavior plays a large role in understanding how stress affects people, how human forces and adaptive capabilities contribute to limiting the negative effects of stress [8].

From a practical point of view, studying the problem of coping with difficulties (coping) is directly related to the importance of maintaining psychological well-being in people experiencing difficult life events, and maintaining the success of productive activities (educational, professional, sports, etc.), despite the setbacks.

According to the definition of T.L. Kryukova, "coping is a purposeful behavior that allows a person to deal with the stress (difficult life situations) in ways that are adequate to personal characteristics and situations" [5]. S.A. Khazova defines "coping is adaptive behavior used in stressful situations to reduce the effects of stress to regulate emotional states in order to stop, avoid or endure the effect of a stressor." In the works of V.M. Yaltonsky and N.I. Sirota coping is understood as a strategy of actions applied by a person in a situation of psychological threat, in particular, in conditions of adaptation to the disease as a threat to physical, personal and social wellbeing [9]. From the point of view of E.I. Chekhlatogo and N.V. Veselova, the concept of coping should be considered as active individual efforts aimed at mastering a situation or problem $[10,11]$.

The psychological purpose of coping behavior is to adapt a person to the requirements of an unfavorable life situation as best as possible, allowing him to master it, weaken or mitigate negative factors and reduce the destructive effect of the situation [12].

In modern science there is a large number of studies which focus on the research of various psychological, ethnopsychological, physiological, social and medical aspects of coping strategies (Blizer A., Khaim E., Ringer H., Tommen M., Vetrova II, Korzhova E. Yu., Nabiullina R.R., Tukhtarova I.V., Nartova-Bochaver S.K., Antsyferova L.I., 1994, Kryukova T.L., Wasserman L.I. et al., Lazarus RS, Gurieva S.D., N.E. Vodopyanova, Frydenberg, E. and many others) [3, $4,13]$

A review of the scientific literature suggests that different types of coping strategies have been identified so far, under which it is customary to consider the use of various methods and techniques aimed at overcoming stressful situations [2, 14].

The problem of overcoming stressful and critical situations by an individual is studied by scientists in various fields of knowledge: biology, medicine, psychophysiology, psychology. Increasing negative impact of natural, environmental, social and other adverse conditions on the individual accounts for the sustained interest in this problem.
In this regard, the study of psychological methods of coping with stress as a factor in the successful adaptation of a man in the modern world is of importance.

Of particular interest to most researchers is the problem of personal coping strategies in the context of cultural diversity. The study of cross-cultural features of coping strategies is relevant in connection with the fact that it contributes to a better understanding of the ways of the person's holistic functioning as a subject of activity in a multicultural environment $[6,15,16]$

So far no clear criteria, that reveal the cross-cultural characteristics of coping strategies among representatives of different ethnic groups living in Russia, have been worked out in psychology [2]. There is lack of comparative studies of the coping behavior of young men and women living in different regions of Russia. The influence of the ethnocultural conditions of the social environment and life on the formation of coping strategies among students remains not fully understood. Therefore, there is an urgent need in additional comprehensive studies of the role of ethnopsychological, personal and social factors that contribute to the formation of a constructive coping strategy for representatives of different nationalities of our country [15,17-19]

\section{RESEARCH METHODS}

The main goal of the study is to analyze the cross-cultural characteristics of coping strategies among young men and women representatives of the Russian and Ossetian ethnic groups. Based on the purpose of the study, the following tasks are identified: to conduct a comparative analysis of the ethnopsychological features of coping strategies among students of the Russian and Ossetian ethnic groups, as well as to identify gender differences in the students' preferred coping strategies. The study was conducted using the following set of empirical methods: the author's questionnaire with questions aimed at identifying the socio-demographic characteristics of the respondents (Yu.A. Afanasyeva), the author's questionnaire "Sexual Behavior and Intimate-Personal Attitudes" (V.V. Ilchenko), "Coping behavior in stressful situations" (designed by N. Endler and D. Parker, adapted by T. L. Kryukova) [18, 20.], "COPE: stress coping questionnaire" (developed by K. Carver, M. Scheyer and J. Weintraub, adapted by T.O. Gordeeva, E.N. Osin, EA Rasskazova, OA Sychev, V.Yu. Shevyakhova) [21] and the questionnaire "Coping strategies indicator" (by J. Amirkhan). The research results were processed and analyzed using mathematical and statistical methods, using Excel and SPSS.13.0 computer programs, also, Student's t-test and the rPearson correlation coefficient were used.

\section{STUDY SAMPLE}

The study was conducted in the Republic of North OssetiaAlania, the city of Vladikavkaz, whose residents are mostly Ossetians. The Russians constitute an ethnic minority in the territory of this region, they make up an ethnic community, preserving their identity, specific national features of culture, conscious of their differences. Representatives of the Russian ethnic group living in the republic and taking part in the study 
are Cossacks who have been living here for about 100 years (53 people), as well as Russians, who came mainly during the Soviet period (50 people).

The sample included 216 people (105 young men and 111 girls) aged 18 to 23 years, the average age of the respondents is 21.5. The study involved students from various universities of Vladikavkaz. According to personal ethnic identity, the following groups were interviewed: representatives of the Ossetian ethnic group - 113 people (56 young men, 57 girls); representatives of the Russian ethnic group -103 people (49 young men, 54 girls)

\section{RESEARCH RESULTS}

According to the data obtained, representatives of the Russian ethnic group more often make use of problemoriented coping in a problem situation $(\mathrm{t}=3.18$, at $\mathrm{p} \leq 0.01)$, which includes a high degree of self-control and belief in one's own resources when dealing with difficult life situations. The data obtained indicate that Russians are characterized by control of emotions and restraint, and with them the careful planning of actions and analysis of the problem prevail. Thus, Russians in a stressful situation are aimed at changing the existing difficult circumstances, by searching useful information and active actions to eliminate them.

It was determined that the Russian respondents more often than the Ossetians in cases of difficult life situations use the strategy of "active coping" $(\mathrm{t}=2.50$, at $\mathrm{p} \leq 0.01)$, suggesting phased actions aimed at overcoming a stressful situation. It was found that in the Russian sample, respondents more often resort to "social distraction" as a form of coping behavior $(\mathrm{t}=$ 2.84 , with $\mathrm{p} \leq 0.01$ ), in which the individual tries to socialize more actively, to enter into social contacts with other people while dealing with problem situations.

In their turn, in the Ossetian sample, the use of emotionally oriented coping $(\mathrm{t}=-1.98$, at $\mathrm{p} \leq 0.05)$ was more often observed, which was reflected in the excessive manifestation of one's own feelings and emotions caused by an unpleasant situation, as well as with active indignation and protest in relation to difficulties, a state of hopelessness, an experience of anger and blaming oneself and others.

The representatives of the Ossetian ethnic group more often highlight their own emotions $(\mathrm{t}=-3.28$, at $\mathrm{p} \leq 0.01)$, which is manifested in focusing on negative emotions in stressful situations, expressing subjective experiences and demonstrating their feelings. It was determined that the respondents of the Ossetian sample are distinguished by the frequent use of "denial" as coping behavior with stress in a critical situation $(\mathrm{t}=-3.70$, at $\mathrm{p} \leq 0.01)$. This suggests, that Ossetians more often than Russians do not want to believe in what happened, and thus try to deny its reality in every way. Also, in case of a difficult life situation, representatives of the Ossetian ethnic group have a "behavioral avoidance of the problem" strategy $(\mathrm{t}=-3.42$, at $\mathrm{p} \leq 0.01)$, which is manifested in the refusal to achieve the desired goal and the inability to regulate efforts aimed at overcoming stress.

Examining the individual psychological characteristics of these ethnic groups, it was found that Russians showed more respect for others $(\mathrm{t}=2.50$, with $\mathrm{p} \leq 0.01)$. Perhaps this suggests, that the Russians tend to have positive attitudes towards others, feel the need to be with people, are responsive, understand others well, feel personal responsibility for their well-being, and tolerate shortcomings. They know how to empathize, support public events and feel responsible for a common cause, conscientiously and responsibly carry out their assignments. Interacting with others, they try to avoid disagreements, prefer to cooperate with people rather than to compete.

The representatives of the Ossetian ethnic group are more characterized by self-respect $(\mathrm{t}=2.53$, with $\mathrm{p} \leq 0.01)$, which is characterized by a person's desire to be independent and selfsustained; they are always ready to defend their interests in the competition and, as a rule, strive for excellence.

According to the data obtained, young men more often than girls in stressful situations use problem-oriented coping $(\mathrm{t}$ $=-2.33$ at $\mathrm{p} \leq 0.05)$. This indicates that the young men are characterized by control of emotions and restraint, careful planning of actions in solving problems, with them the analysis of the situation prevails. Thus, young men are more focused than women on changing the prevailing problematic circumstances by searching for useful information and active actions

It was determined that in stressful situations, young men prove more prudent $(\mathrm{t}=-2.42$ at $\mathrm{p} \leq 0.05)$ and inquisitive $(\mathrm{t}=$ 2.08 at $\mathrm{p} \leq 0.05)$ than girls. This once again suggests that young men are characterized by a high level of volitional regulation of behavior and self-control.

However, it should be noted that avoidance-oriented coping $(\mathrm{t}=-2.21$ at $\mathrm{p} \leq 0.05)$ is also more common among young men. Young men are more prone to get distracted from a stressful situation with the help of a cheerful, noisy company, alcohol, tobacco and / or the use of psychoactive drugs, thus trying to avoid contact with their environment and get away from solving existing problems.

However, we also found that Russian youths are more likely than Ossetian youths to have a "distraction" from the problem situation $(\mathrm{t}=2.30$, at $\mathrm{p} \leq 0.05)$, which is reflected in the desire to temporarily get away from solving problems with the help of alcohol, medicines, immersion in favorite passtime, travelling, fulfillment of cherished desires. As the results of the study showed, the Russian youths also more often than Ossetian youths use the "problem avoidance" coping strategy $(\mathrm{t}=3.61$, at $\mathrm{p} \leq 0.01)$, which implies behavior ignoring thoughts, yielding, passivity, and desire to remain peaceful.

In its turn, the dominance of emotionally oriented coping was found among girls $(\mathrm{t}=-2.78$ at $\mathrm{p} \leq 0.01)$, which manifests itself in a focus on unpleasant emotions and feelings. In the course of the study, it was found that girls more often than boys deny what happened $(t=-2.27$ at $\mathrm{p} \leq 0.05)$, refusing to believe in what is happening or trying to reject its reality. As the results show, in a stressful situation, girls more often than boys turn to God, faith and religion for help.

It was revealed that in a problem situation, girls have a higher level of tension $(t=-2.29$ at $\mathrm{p} \leq 0.05)$ than boys. This may suggest that girls, in case of failure, are prone to fall into despair or depression. 
According to the study, among the Russian girls such behavioral strategies prevail as: problem solving planning $(\mathrm{t}=$ 2.44 at $\mathrm{p} \leq 0.05)$ and active coping with stress $(\mathrm{t}=3.22$ at $\mathrm{p} \leq 0.05$ ), which indicates the desire of Russian girls to cope with a difficult stressful situation through a focused analysis of the situation and possible behaviors, developing a strategy for resolving the problem, planning their own actions based on objective conditions, past experience and available resources.

In recent decades, there has been a change in the behavior, values and premarital attitudes of youth. Significant changes are observed in the sexual behavior of young men and girls. It should also be noted that often young people receive conflicting and inaccurate information on gender issues from the media, which further contributes to the growth of tension, anxiety. In future, this can adversely affect intersexual relationships, as well as the adaptive abilities of a person [11, 20-22] Coping strategies are often considered as the most important forms of adaptation processes and the individual's response to stressful situations. In the period of youth, satisfaction with inter-sexual relations is one of the essential factors of individual's well-being, while unsuccessful relationships often contribute to the manifestation of anxiety, depression, and feelings of loneliness [11, 22, 23]

It is worth emphasizing that in adolescence, relations between the sexes are of great importance and are an important factor in the development of personality

A study of the sexual behavior of girls by V.V. Ilchenko, showed that the level of activity in sexual behavior is significantly lower among Ossetian girls compared with Russian respondents. As they grow older, the differences become somewhat leveled. However, the lack of experience of sexual behavior in adolescence leads to the occurrence or increase of anxiety, neurotization. The Ossetian respondents are concerned about the lack of experience of dating, kisses, petting, and sexual life. At the same time, Russian girls in this age period worry only about their own sexual inexperience. There are differences in personal reactions to certain forms of sexual activity in adolescence between Ossetian and Russian respondents. Russian girls who do not have sexual experience have a higher level of personal anxiety, Ossetian girls have a higher level of neuroticism compared to active subjects. It was also possible to establish general and specific features of subjective psychological distress associated with sexual behavior. The psychosexual well-being of the Ossetian respondents is mostly affected by ethnic and social factors, while with the Russian respondents more relevant are individual-personal attitudes, assessments of their own experience of sexual behavior [12].

Our correlation analysis showed that sexually experienced young men are more likely to use the coping strategy "search for social support" $(\mathrm{r}=0.325$ at $\mathrm{p} \leq 0.05)$. This is characteristic of the representatives of both Ossetian and Russian ethnic groups. Consequently, they seek help from the social environment to effectively solve problems. The young men who have no sexual relations use the coping strategy "problem solving" $(\mathrm{r}=0.422$ at $\mathrm{p} \leq 0.05)$, preferring to independently resolve problems that arise, using all available forces. The opposite trend was revealed in the female sample. This coping strategy is used by sexually experienced girls $(r=0.424$ at $\mathrm{p} \leq 0.05)$. While sexually inexperienced girls use the "problem avoidance" coping strategy $(\mathrm{r}=0.375$ at $\mathrm{p} \leq 0.05)$. In other words, the girls who have no intimate relationships are more likely to avoid independent solution to the problem. Moreover, the ethnicity of the girls is neutralized in this respect.

\section{CONCLUSION}

It was determined that the contents of coping behavior depend on gender, ethnicity, as well as sexual experience. For the representatives of the Russian ethnic group, socially acceptable coping strategies are: positive reevaluation, problem solving planning, self-control. At the same time, the leading coping strategy is the problem-oriented one. It can be assumed that the Russians are characterized by the suppression and restraint of their emotions, overcoming negative experiences due to positive reassessment.

The Ossetians, on the other hand, show dominance of expressiveness, manifested in light attitude to life, more confidence in their feelings and intuition, rather than in the common sense. Among them, concentration on negative feelings and emotions associated with a stressful situation is more common. It should also be noted that the Ossetians are more conservative, which indicates that their main value is their commitment to traditional values and orders, preserving the traditions of their ethical group.

It should be emphasized that young men in stressful situations often choose constructive coping strategies, such as planning and the search for social support of an instrumental nature. This may indicate that young men tend to think about how to act in relation to a difficult life situation and develop tactics of behavior. They are more likely to seek advice, help, or information from the social environment. However, there are ethnic differences in youth coping strategies. So, Russian young men are characterized by avoidance and social distraction, while the Ossetian youths are characterized by denial and deterrence of coping.

Girls are characterized by a predominance of an emotionally oriented coping strategy, which manifests itself in a focus on unpleasant emotions and feelings. Girls more often than boys deny what happened, refusing to believe in what is happening and trying to reject the reality, they tend to seek help from God, faith and religion. Also, girls are more likely to respond to a problem situation with humor, laughter or a joke.

Ethnic differences in coping behavior among girls were also revealed. The behavior of the Russian girls is characterized by self-control, in which the overcoming of negative feelings in connection with a difficult life situation occurs through targeted suppression and restraint of emotions, as well as minimizing their influence on assessing the situation and choosing a behavior strategy, high control of behavior, and the desire for self-control [14] In their turn, among the girls of the Ossetian ethnic group, concentration on emotions and their expression, as well as behavioral escape from the problem prevail.

The study showed that young men who have no experience in sexual relations are more likely to use the coping strategy "problem solving". In contrast, sexually experienced 
respondents are more likely to use the coping strategy "seeking social support". This is characteristic of representatives of the Ossetian and Russian ethnic groups. The girls who do not have sexual experience have a greater tendency to use the coping strategy "problem avoidance" (typical for both Ossetians and Russians), while sexually experienced respondents use the coping strategy "problem solving".

The present study confirms the cross-cultural characteristics of the representatives of the Ossetian ethnic group analyzed in the works of Gurieva S.D., Gutsunaeva S.V., Doeva L.I., Dreeva O.I., Ilchenko V.V., Olisaeva A.M., Khudalova M.Z. [2, 6, 7, 12, 17,24]

The cross-cultural characteristics of the representatives of the Ossetian ethnic group were formed as a result of the influence of climatic conditions, the social life peculiarities, the specifics of spiritual life, the peculiarities of the forms and methods of the national education system: the prevalence of prohibitive measures in controlling child behavior, the prevalence of negative sanctions over positive ones, a regressive control, which results in excessive emotionality, rather than in the ability to independently and flexibly control their behavior. For the most Ossetians communitarian values (their own nation, clan, family) are dominant [7]. Ethnic features of coping strategies are based on values, traditions, norms of behavior, attitudes. So the coping strategies of Russian culture as a whole are the same for both men and women. In the Ossetian culture, values and the traditionally established gender division of social roles in the family limit the strategies of woman's coping behavior [8, 23]

Thus, the data obtained indicate cross-cultural differences in coping behavior among representatives of the Russian ethnos, who, residing in a multicultural environment, are more tolerant, open-minded and friendly to others, and the Ossetian ethnos, who adhere to their ethnic customs and traditions.

The empirical results can become the basis for the theoretical base of new research on coping strategies among representatives of different ethnic groups, as this helps to enrich scientific ideas on the problem of the influence of cross-cultural factors on the formation of coping strategies in boys and girls $[24,25]$. The results of the study can be used in developing recommendations on the organization of sociopsychological services in multicultural regions, as well as in developing training programs in stress psychology, personality psychology, ethnic psychology, sexology, and developmental psychology. It is also possible to use the described data in the practice of psychological counseling for young men and women experiencing difficult life situations.

\section{References}

[1] J.H. Amirkhan "Factor analiticaly derived measure of coping: the strategy indicator" J. of Personality and Social Psychology vol. 59, pp 1066-1074, 2008.

[2] Yu.A. Afanasyev "Cross-cultural, gender and age peculiarities of coping behavior among Ossetians and Russians" Problems of modern pedagogical education. Iss. 63. Part 2. pp. 296-299.

[3] Yu.A. Afanasyev "The study of cross-cultural characteristics of coping behavior among Russians and Ossetians" Psychology. Historical and critical reviews and modern research..Vol. 8, No. 1A,. pp. 72-76, 2019.

[4] L.I. Antsyferova "Personality in difficult life conditions: rethinking, transformation of situations and psychological protection" Psychologica Journal. vol. 15. No. 1. pp. 3-18. 1994

[5] C. H. B. Kuo. "Coping, acculturation, and psychological adaptation among migrants: a theoretical and empirical review and synthesis of the literature" Health Psychology and Behavioral Medicine vol. 2,. pp.1633. 2014.

[6] L.I. Doeva "The image of the spouse in the perception of men and women in the Republic of North Ossetia-Alania": diss. Cand. psychol. Sciences: 19.00.05. St. Petersburg, 2017, p.208.

[7] L.I. Doeva, V.L. Sitnikov "The idea of spouses in the minds of men and women in the Republic of North Ossetia-Alania" Monograph Vladikavkaz: SOGPI Publishing House, 2018 .p.201

[8] V.L Sitnikov, V.V. Ilchenko "Premarital sexual settings of girls in a multicultural environment" ZabGU vol. 11. No. 5. pp. 107 - 114, 2016

[9] R.S. Lazarus Puzzles in the Study of Daily Hassles.,J. Behav. Med. vol 3, 2001, pp. 375-384

[10] S.D. Gurieva "Interethnic relations: an ethnic factor in intergroup relations" Bulletin of the Yakut State University.vol. 5. No. 4. pp. 79-83, 2008

[11] I.I. Vetrova "The connection of coping behavior with behavior contro and psychological protection in the system of self-regulation Concurrent Behavior: Current State and Prospects M.: Publishing House "Institute of Psychology RAS", 2008. pp. 179-196

[12] V.V. Ilchenko "Ethnic pecularities of psychosexual development of females in a multicultural environment: by the example of the Republic of North Ossetia-Alania:" diss. Cand. psychol. Sciences: 19.00.13. St. Petersburg, 2010. p. 279

[13] T. Kasyanova "About the Russian national character" M .: Publishing house of the Institute of the National Model of Economics, 1994. 267c.

[14] T.L Kryukova. "Psychology of coping behavior: current state and psychological, sociocultural perspective" Bulletin of KSU named after ON. Nekrasov. No. 5, .pp.184-188, 2013.

[15] S.D. Gurieva Interethnic Relations: "Models of Ethnic Identity and Transformational Processes at Present" Bulletin of the North Ossetian State University named after Kost Levanovich Khetagurov.. No. 1. pp. 101-107 2015

[16] R.S. Lazarus "Toward better research on stress and coping" American Psychologist vol. 55 (6), pp. 665-673, 2000

[17] S.D. Gurieva "Intergroup relations as an area of socio-psychologica research" Society.. No. 1 (1). pp. 75-82 2014

[18] V.V. Ilchenko, V.L. Sitnikov N.V. Parnyuk F. G. "Sanakoeva Intimate Relationships of Youth in Russia" C.T. Hill Intimate Relationships Across Cultures: A Comparative Study. Cambridge University Press, pp. $47-50,2019$

[19] I.S. Kon Teenage sexuality on the threshold of the 21 st century. Sociopedagogical analysis. Dubna: Phoenix,$+ 2001.208 \mathrm{~s}$

[20] E. S. Kim "Cross-cultural analysis of the influence of ethnopsychological characteristics on the coping behavior of representatives of the Japanese and Russian ethnic groups". Humanitarian, socio-economic and social sciences,. No. 5. pp. 99-107, 2013

[21] R.S. Lazarus A.D. Kanner S. Folkman "Emotions: a cognitive phenomenological analysis" Emotion. Theory, Research and Experience vol. 1 , pp. 185-217, 2000 
[22] R.H Moos, J.A. Schaefer "The crisis of physical illness: An Overview and Conceptual Approach" Coping with physical illness. pp. 3-21 2001

[23] Zeindr M. Life events and coping resources as predictors of stress symptoms in adolescents // Pers. Individ. Diff. - Volume 11 (7), 2000. P. 693-703.
[24] Emelyanov Yu.P. Introduction to cultural anthropology - St. Petersburg: Publishing House of St. Petersburg State University, $1992.156 \mathrm{~s}$

[25] Perrez M. Stress, coping and health. A situation-behavior approach. Theory, methods, applications. Seattle: Hogrefe and Huber Publishers, 2001 